\title{
RESEARCH
}

Open Access

\section{Predictive factors for pleural drainage volume after uniportal video-assisted thoracic surgery lobectomy for non-small cell lung cancer: a single-institution retrospective study}

\author{
Ming-bo Tang ${ }^{1}$, Jia-lin Li', Su-yan Tian², Xin-liang Gao ${ }^{1}$ and Wei Liu' ${ }^{1 *}$
}

\begin{abstract}
Objective: To identify the predictive factors associated with pleural drainage volume (PDV) after uniportal videoassisted thoracic surgery (VATS) lobectomy for non-small cell lung cancer (NSCLC).

Methods: A total of 440 consecutive NSCLC patients who underwent uniportal VATS lobectomy were enrolled in this study between November 2016 and July 2019. Thirty-four parameters, including patients' clinicopathological characteristics and other potential predictors were collected. Daily drainage volume was summed up as PDV. Univariate analysis and multivariate regression models were fitted to identify independent predictive factors for PDV.

Results: The median PDV was $840 \mathrm{ml}$ during the median drainage duration of 4 days. A strong correlation was observed between PDV and drainage duration (correlation coefficient $=0.936$ ). On univariate analysis, age, forced expiratory volume in $1 \mathrm{~s} \%$ predicted (FEV1\%), left ventricular ejection fraction (LVEF), operation time, serum total protein (TP), and body mass index (BMI) showed a significant correlation with PDV $(P$ value $<0.001,<0.001,0.003$, $0.008,0.028$, and 0.045 , respectively). Patients with smoking history $(P=0.030)$ or who underwent lower lobectomy $(P=0.015)$ showed significantly increased PDV than never smokers or those who underwent upper or middle lobectomy, respectively. On multivariate regression analysis, older age $(P<0.001)$, lower FEV1\% $(P<0.001)$, lower $\operatorname{LVEF}(P=0.011)$, lower TP $(P=0.013)$, and lower lobectomy $(P=0.016)$ were independent predictors of increased PDV.
\end{abstract}

Conclusions: Predictive factors of PDV can be identified. Based on these predictors, patients can be treated with tailored individualized safe chest tube management.

Keywords: Predictive factors, Pleural drainage volume, Uniportal VATS lobectomy, Non-small cell lung cancer

* Correspondence: liuweihospital@126.com

'Department of Thoracic Surgery, The First Hospital of Jilin University, 71

Xinmin Street, Changchun, Jilin 130021, China

Full list of author information is available at the end of the article

(c) The Author(s). 2020 Open Access This article is licensed under a Creative Commons Attribution 4.0 International License, which permits use, sharing, adaptation, distribution and reproduction in any medium or format, as long as you give appropriate credit to the original author(s) and the source, provide a link to the Creative Commons licence, and indicate if changes were made. The images or other third party material in this article are included in the article's Creative Commons licence, unless indicated otherwise in a credit line to the material. If material is not included in the article's Creative Commons licence and your intended use is not permitted by statutory regulation or exceeds the permitted use, you will need to obtain permission directly from the copyright holder. To view a copy of this licence, visit http://creativecommons.org/licenses/by/4.0/. The Creative Commons Public Domain Dedication waiver (http://creativecommons.org/publicdomain/zero/1.0/) applies to the data made available in this article, unless otherwise stated in a credit line to the data. 


\section{Introduction}

Postoperative chest tube placement to drain pleural fluid is an important procedure after thoracic surgery. Pleural drainage volume (PDV) after the operation is directly related to the duration of drainage. A higher PDV will lead to prolonged placement of the chest tube and result in an uncomfortable experience of pain, immobilization, increased risk of infection [1, 2], as well as increased length and cost of hospitalization subsequently [3]. Besides, very early removal of the chest tube in patients with excessive PDV might also cause frequent chest tube replacement because of symptomatic effusion [4].

Thus, the timing of chest tube removal has always been a controversial issue. Empirically, the threshold of daily drainage volume depends on the experience of different surgeons [5]. This threshold varies widely; it can be $2 \mathrm{ml} / \mathrm{kg}$ body weight [6], or it can be $100 \mathrm{ml}$ [7], 200 $\mathrm{ml}$ [8], or even $500 \mathrm{ml}$ per day [9]. Occasionally, the daily drainage volume is not considered during chest tube removal $[10,11]$. However, the uniform standard may not be the appropriate threshold level for different patients as the ability of the pleura for filtration and reabsorption vastly differs from patient to patient. Under this circumstance, a thoracic surgeon should be able to accurately predict the drainage volume for appropriate chest tube management.

To the best of our knowledge, no study has systematically investigated the predictive factors for total PDV after lobectomy. To address this issue, we retrieved the daily drainage records of non-small cell lung cancer (NSCLC) patients who underwent uniportal videoassisted thoracic surgery (VATS) lobectomy and we extensively analyzed the potential predictive factors associated with PDV.

\section{Methods \\ Patients}

The present study enrolled 440 consecutive NSCLC patients who underwent uniportal VATS lobectomy and systematic lymph node dissection between November 2016 and July 2019. All patients were screened according to the following exclusion criteria: co-existence of severe underlying diseases before the operation; in combination with pleural metastasis or pleural nodules; lobectomy for more than one lobe; chemo- or radio-therapy prior to surgery; anesthesia and operation time more than $3 \mathrm{~h}$; detection of extensive pleural adhesion intraoperatively; intraoperative blood transfusion; intraoperative blood

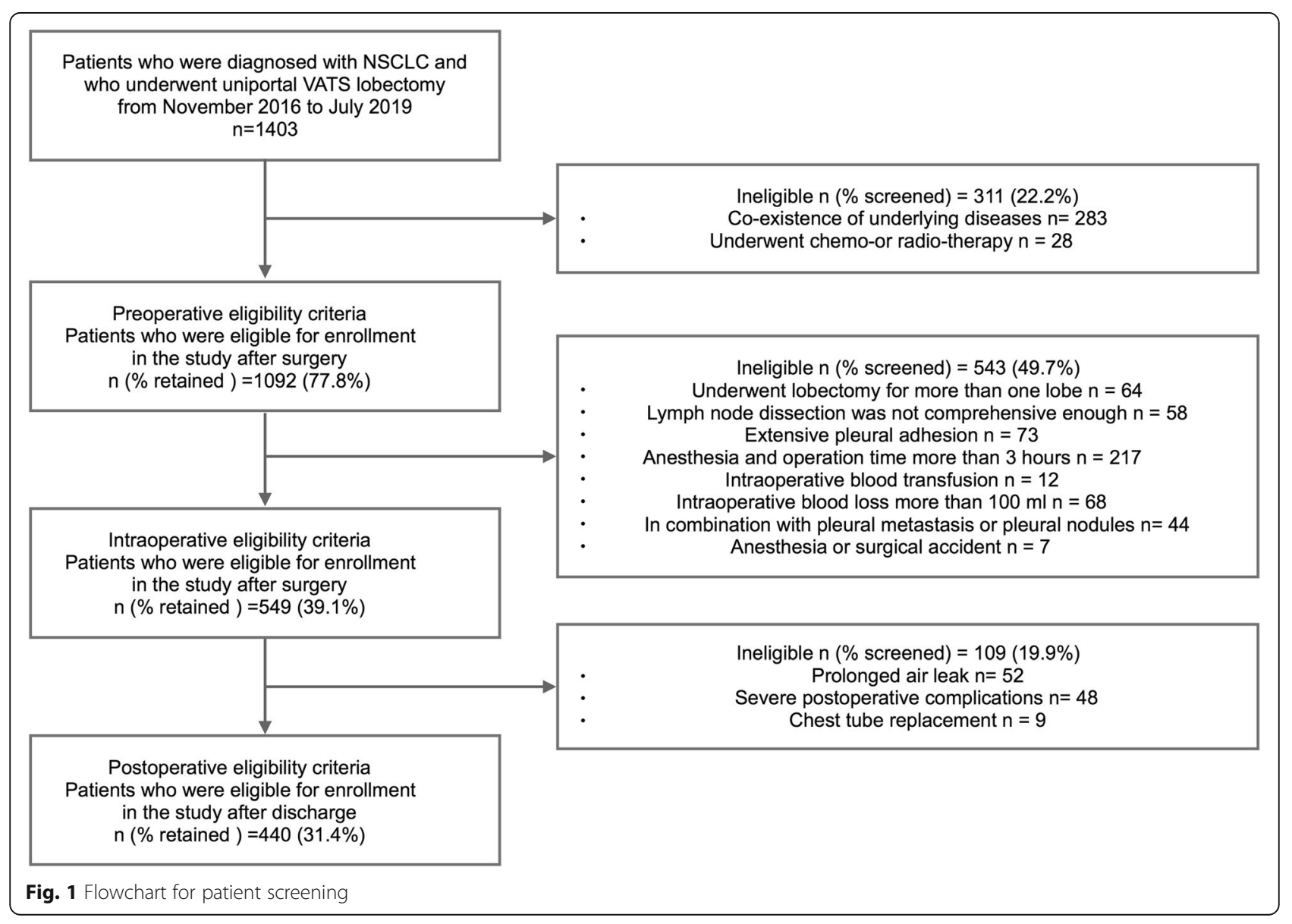


loss more than $100 \mathrm{ml}$; anesthesia or surgical accident; severe postoperative complications; prolonged air leak; and chest tube replacement. The flow chart for selection of patients is shown in Fig. 1. The tumor, node, metastasis (TNM) staging was in accordance with the International Association for the Study of Lung Cancer (IASL C) staging system (the 8th Edition) [12]. This study was approved by the Ethics Committee of First Hospital of Jilin University. Informed consent for use of the medical data in this study was obtained from the patients.

\section{Perioperative management}

All patients underwent routine preoperative examination and blood tests in our hospital. The enrolled patients underwent uniportal VATS lobectomy through an incision 4-5 cm long over the fifth intercostal space under single lung ventilation. The pulmonary vessels and bronchi were individually dissected, stapled, or ligated and then they were divided. Incomplete fissures were developed by mechanical staplers. Lobectomy and systematic lymph node dissection were performed in all enrolled patients. Mediastinal lymph nodes were completely resected at stations $4 \mathrm{~L}, 5,6,7,8$, and 9 for left-sided cancers; and at stations $2 \mathrm{R}, 4 \mathrm{R}, 7,8$, and 9 for rightsided cancers. After confirmation of achievement of pneumostasis and hemostasis, a chest tube was conventionally placed through the incision over the fifth intercostal space apically before chest closure. The tube was connected to a drainage bucket with a negative pressure of $8 \mathrm{~cm} \mathrm{H} \mathrm{H}_{2} \mathrm{O}$ suction during the first 2 days after surgery. Routine chest $\mathrm{X}$-ray was performed on the first day after the operation, and it was reperformed before chest tube removal.

The total PDV was calculated based on the records obtained by a particular doctor every $24 \mathrm{~h}$. Postoperative management mainly focused on early ambulation, antibiotic prophylaxis, respiratory rehabilitation, and anticoagulation. The chest tube was removed once the following conditions were fulfilled: chest X-ray showed satisfactory lung re-expansion; there was absence of air leak in the chest drainage bucket; there was absence of thick bloody, purulent, or cloudy pleural fluid; and the drainage volume was not more than $200 \mathrm{ml}$ on the day of chest tube removal.

\section{Statistical data analysis}

A total of 34 parameters of patients were analyzed in this study. Continuous variables were summarized as mean \pm standard deviation for the normally distributed data and as median (interquartile range [IQR]) for the non-normally distributed data. In univariate analysis of a continuous variable, Spearman correlation coefficients were calculated between PDV and the continuous variable. For a categorical variable, Mann-Whitney $U$ tests were performed for comparison between two groups and Kruskal-Wallis test was performed for comparison among three or more groups. Variables with a $P$ value < 0.1 on univariate analysis were entered into multivariate regression analysis with backward selection to identify independent predictors of PDV, wherein categorical variables were converted into dummy variables, such as 0 or 1 for patients with or without smoking history. Values of $P<0.05$ were considered statistically significant. All analyses were performed with Statistical Package for Social Sciences (SPSS) version 23.0 (SPSS Inc., Chicago, IL, USA). Graphs were created with the aid of the GraphPad Prism version 8.2.0.

\section{Results}

The total 440 patients included 268 women and 172 men, and the median age was 60 years. The median PDV was $840 \mathrm{ml}$ during the median drainage duration of 4 days. Further details of the clinicopathologic characteristics are shown in Table 1 . The volume of daily drainage on the particular postoperative day (POD) is

Table 1 Clinicopathological characteristics of the enrolled patients

\begin{tabular}{ll}
\hline Parameters & \\
\hline Age (years, IQR) & $60(53-65)$ \\
Gender male $(n, \%)$ & $172(39.1 \%)$ \\
Smoking history $(n, \%)$ & $130(29.5 \%)$ \\
TNM staging $(n, \%)$ & \\
IA & $241(54.8 \%)$ \\
IB & $99(22.5 \%)$ \\
IIA & $16(3.6 \%)$ \\
IIB & $53(12.0 \%)$ \\
IIIA & $21(4.8 \%)$ \\
IIIB & $5(1.1 \%)$ \\
IV & $5(1.1 \%)$ \\
Pathology $(n, \%)$ & \\
Adenocarcinoma & $385(87.5 \%)$ \\
Squamous carcinoma & $46(10.5 \%)$ \\
Others & $9(2.0 \%)$ \\
Surgical location $(n, \%)$ & \\
LUL & $104(23.6 \%)$ \\
LLL & $79(18 \%)$ \\
RUL & $121(27.5 \%)$ \\
RML & $39(8.9 \%)$ \\
RLL & $97(22 \%)$ \\
Duration of drainage (days, IQR) & $4(3-5)$ \\
PDV (ml, IQR) & $840(570-1370)$ \\
\hline
\end{tabular}

IQR interquartile range, TNM tumor, node, metastasis, LUL left upper lobe, LLL left lower lobe, $R U L$ right upper lobe, $R M L$ right middle lobe, $R L L$ right lower lobe 
shown in Fig. 2, and it showed a general decreasing trend from the first day after the operation. A strong correlation was observed between PDV and duration of drainage (correlation coefficient, 0.936; $P<0.001$ ).

Univariate correlation analysis showed that age, operation time, and BMI were positively correlated with PDV ( $P$ value, $<0.001,0.008$, and 0.045 , respectively). In contrast, FEV1\%, LVEF, and TP showed a negative correlation with PDV ( $P$ value, $<0.001,0.003$, and 0.028, respectively). The correlations between PDV and each factor with statistical significance are shown in Fig. 3. After using a less stringent cut-off of 0.1 for $P$ values, statistically significant factors, such as left ventricular fractional shortening (LVFS), serum albumin (ALB), activated partial thromboplastin time (APTT), white blood cell count (WBC), carbon monoxide lung diffusion capacity \% predicted (DLCO\%), serum creatinine (CRE), prothrombin time (PT), and international normalized ratio (INR) were included in the multiple regression analysis $(P$ value $0.059,0.076,0.063,0.056,0.063,0.081$, 0.089 , and 0.091 , respectively; Table 2). The correlations between PDV and other parameters were not statistically significant, including aspartate aminotransferase (AST), alanine aminotransferase (ALT), blood urea nitrogen
(BUN), thrombin time (TT), fibrinogen (FIB), red blood cell count (RBC), platelet count (PLT), hemoglobin $(\mathrm{Hb})$, blood glucose, and erythrocyte sedimentation rate (ESR).

Patients with smoking history showed a significantly higher PDV compared with never smokers $(900 \mathrm{ml}$ vs. $830 \mathrm{ml}$; $=0.030$; Table 3; Fig. 4a). Among the patients with smoking history, the smoking index showed a positive correlation with PDV ( $P=0.011$; Fig. 4b). There was no statistically significant difference in PDV between male and female patients $(P=0.167)$. Among PDVs after different types of lobectomies, PDV after left lower lobectomy was the highest, while PDV after right middle lobectomy was the lowest. Overall, the PDV levels among patients with different types of lobectomy differed substantially ( $P=0.031$; Table 3 ; Fig. 5a). Patients who underwent lower lobectomy had a significantly higher PDV of $910 \mathrm{ml}$ compared to patients who underwent upper or middle lobectomy and showed a PDV of $805 \mathrm{ml}(P=0.015$; Table 3; Fig. $5 \mathrm{~b})$. No significant difference in PDV was observed in patients who underwent lobectomy on the left side or the right side $(P=0.152)$. Although PDV slightly increased by the stage of the tumor, the difference was not statistically significant.

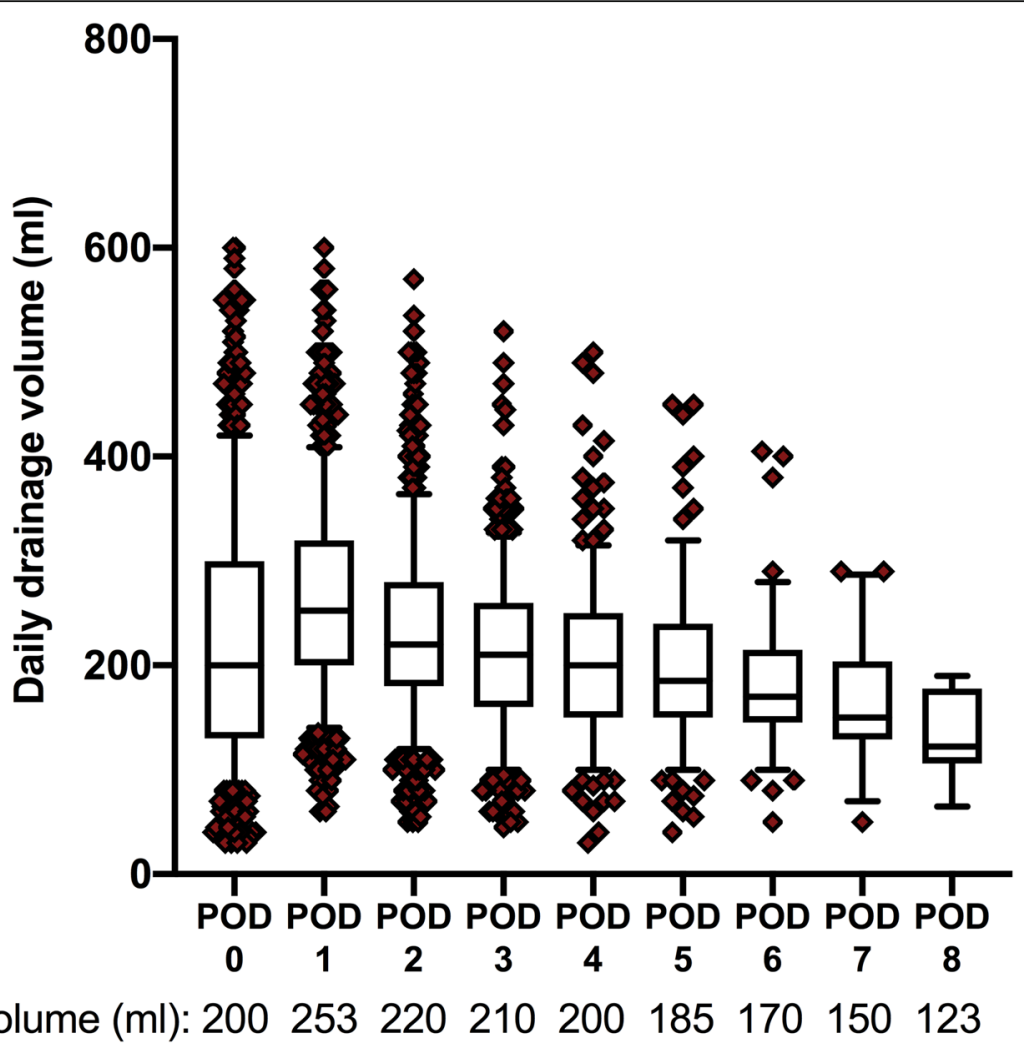

Fig. 2 Daily drainage volume is shown in the form of a graph. The box plots represent IQRs. The lower and upper bars show the 10th percentile and the 90th percentile, respectively; the circles represent the outliers. The median drainage volumes on each POD are also presented. POD postoperative day, IQR interquartile range 


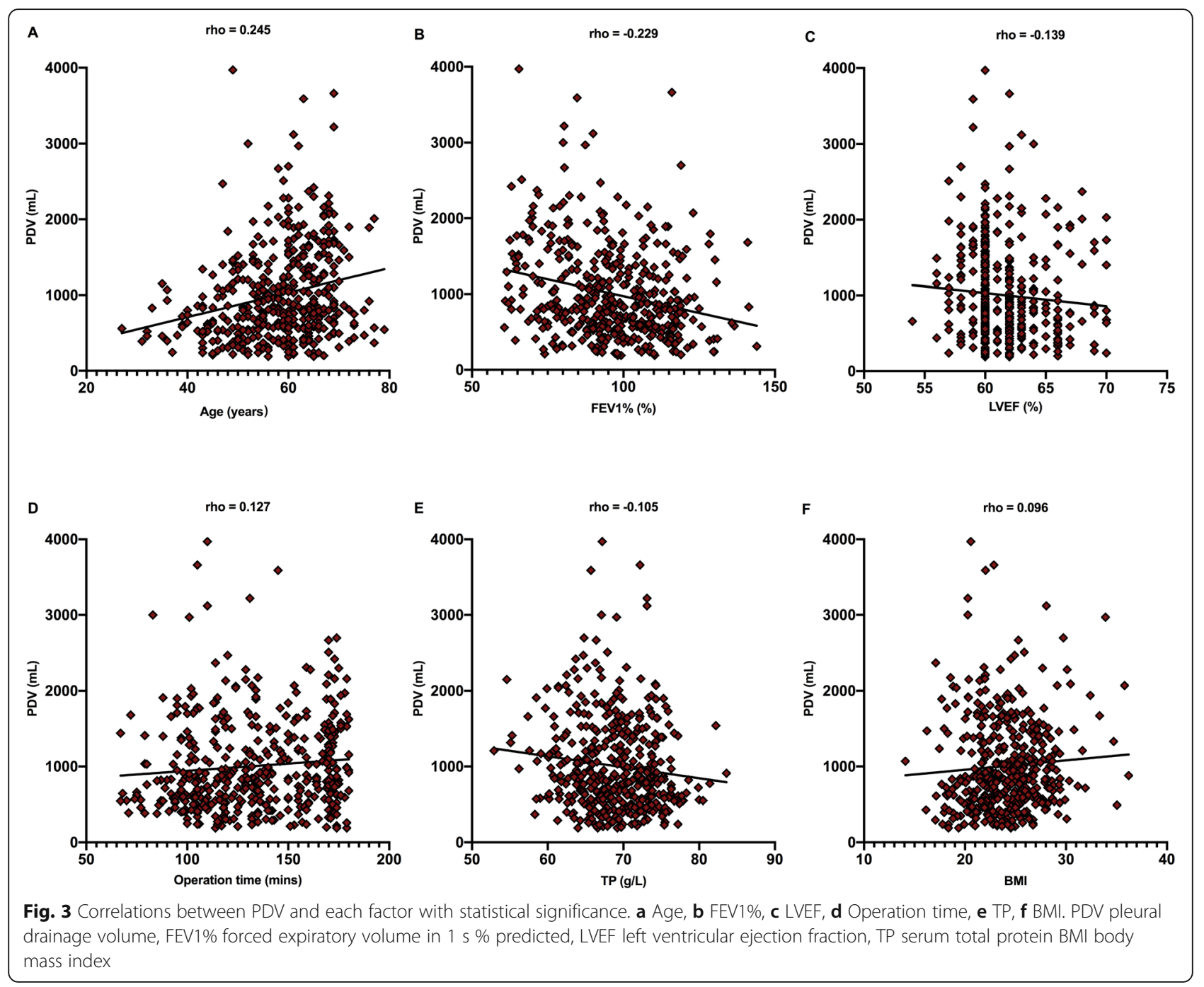

With respect to the T-stage, the PDVs of $\mathrm{T} 1, \mathrm{~T} 2, \mathrm{~T} 3$, and T4 stage patients were $810,865,972.5$, and $1020 \mathrm{ml}$, respectively $(P=0.119)$. With respect to the $\mathrm{N}$-stage, PDVs of N0, N1, and N2 stage patients were 830, 990, and $1045 \mathrm{ml}$, respectively $(P=0.239)$. With respect to TNM staging, PDVs of stage I, II, III, and IV patients were $830,882.5,955$, and $950 \mathrm{ml}$, respectively $(P=$ 0.471 ). In addition, patients with tumor invasion of the pleura had a higher PDV (910 ml vs. $820 \mathrm{ml}, P=0.122)$, and the pathological subtype of patients did not significantly affect the PDV $(P=0.765)$.

Using the multiple backward regression strategy, age $(P<0.001)$, FEV1\% $(P<0.001)$, LVEF $(P=0.011)$, TP $(P=0.013)$, and lower lobectomy $(P=0.016)$ were included in the final model. Specifically, older age, lower FEV1\%, lower TP, lower lobectomy, and lower LVEF were associated with an increase in the total PDV after uniportal VATS lobectomy in NSCLC patients (Table 4).

\section{Discussion}

In a physiological state, pleural fluid enters the pleural space through the parietal pleura via a filtering pressure gradient and it is removed via an absorptive pressure gradient through the visceral pleura, together with lymphatic drainage through the stomas of the parietal pleura. Thus, filtration and reabsorption of pleural fluid maintain a dynamic balance through a negative feedback system between visceral and parietal pleurae [13, 14].

However, the physiological state is inevitably perturbed by the systemic response and local changes due to thoracic surgery. A systemic response is usually induced by anesthesia, surgical injuries, inflammation, and stress. Local changes including intrathoracic tissue injuries and changes such as residual lung over-inflation and alteration of the pulmonary circulation (blood redistribution, the increase in blood flow, velocity, and hydrostatic pressure) can contribute to the development of pleural effusion [15-17]. 
Table 2 The correlation between PDV and factors with $P<0.1$ from continuous variables

\begin{tabular}{llll}
\hline Factors & $\begin{array}{l}\text { Mean } \pm \text { SD } \\
\text { or median (IQR) }\end{array}$ & $\begin{array}{l}\text { Correlation } \\
\text { coefficient }\end{array}$ & $P$ value \\
\hline Age (years) & $60(53-65)$ & 0.245 & $<\mathbf{0 . 0 0 1}$ \\
BMI $\left(\mathrm{kg} / \mathrm{m}^{2}\right)$ & $24.01 \pm 3.34$ & 0.096 & $\mathbf{0 . 0 4 5}$ \\
Operation time $(\mathrm{min})$ & $132(108-164)$ & 0.127 & $\mathbf{0 . 0 0 8}$ \\
FEV1\% (\%) & $96.2 \pm 16.7$ & -0.229 & $<\mathbf{0 . 0 0 1}$ \\
DLCO\% (\%) & $89.1 \pm 16.8$ & -0.089 & 0.063 \\
LVFS (\%) & $32.5 \pm 2.3$ & -0.090 & 0.059 \\
LVEF (\%) & $61.5 \pm 2.8$ & -0.139 & $\mathbf{0 . 0 0 3}$ \\
TP $(\mathrm{g} / \mathrm{l})$ & $68.85 \pm 4.92$ & -0.105 & $\mathbf{0 . 0 2 8}$ \\
ALB $(\mathrm{g} / \mathrm{l})$ & $40.63 \pm 3.44$ & -0.085 & 0.076 \\
CRE $(\mu \mathrm{mol} / \mathrm{l})$ & $64.20 \pm 13.67$ & 0.083 & 0.081 \\
APTT $(\mathrm{s})$ & $27.32 \pm 3.36$ & 0.089 & 0.063 \\
PT $(\mathrm{s})$ & $10.75 \pm 0.83$ & 0.081 & 0.089 \\
INR & $0.96 \pm 0.06$ & 0.081 & 0.091 \\
WBC $\left(10^{9} / \mathrm{l}\right)$ & $5.87 \pm 1.49$ & 0.091 & 0.056 \\
\hline
\end{tabular}

$P D V$ pleural drainage volume, $I Q R$ interquartile range, $B M I$ body mass index, FEV $1 \%$ forced expiratory volume in $1 \mathrm{~s} \%$ predicted, DLCO\% carbon monoxide lung diffusion capacity \% predicted, LVFS left ventricular fractional shortening, $\angle V E F$ left ventricular ejection fraction, TP serum total protein, $A L B$ serum albumin, CRE serum creatinine, $P T$ prothrombin time, $A P T T$ activated partial thromboplastin time, INR international normalized ratio, WBC white blood cell count

Few previous studies aimed to assess the factors affecting PDV after thoracic surgery. Hristova et al. reported that age, chronic obstructive pulmonary disease (COPD), and lower lobectomy were risk factors for large drainage volume on the second day after lobectomy [18]. Kosugi et al. proved that reduced creatinine clearance and thoracic duct resection were risk factors for larger PDV after transthoracic esophagectomy [19]. However, these two studies included various factors that could affect the PDV, such as different surgical procedures, timing of operation, presence of pleural adhesion, and blood transfusion or complications intra- or postoperatively. In order to minimize the potential interference factors, all patients in the present study were analyzed based on the exclusion criteria. It may be an effective way to identify the predictive factors of PDV in patients who are diagnosed with NSCLC and who undergo uniportal VATS lobectomy.

Age is the most representative indicator of the physical condition, and our research showed that it was an independent predictive factor for PDV. This finding was similar to that in the study by Hristova et al [18]. The primary reason why PDV increases with age is increased microvascular dysfunction and hyperpermeability, which are caused by the destruction of endothelial cell adhesion and interstitial matrix-associated proteins [20].

Our research proved that FEV1\% was another significant predictor of PDV. FEV1\% is considered to be an

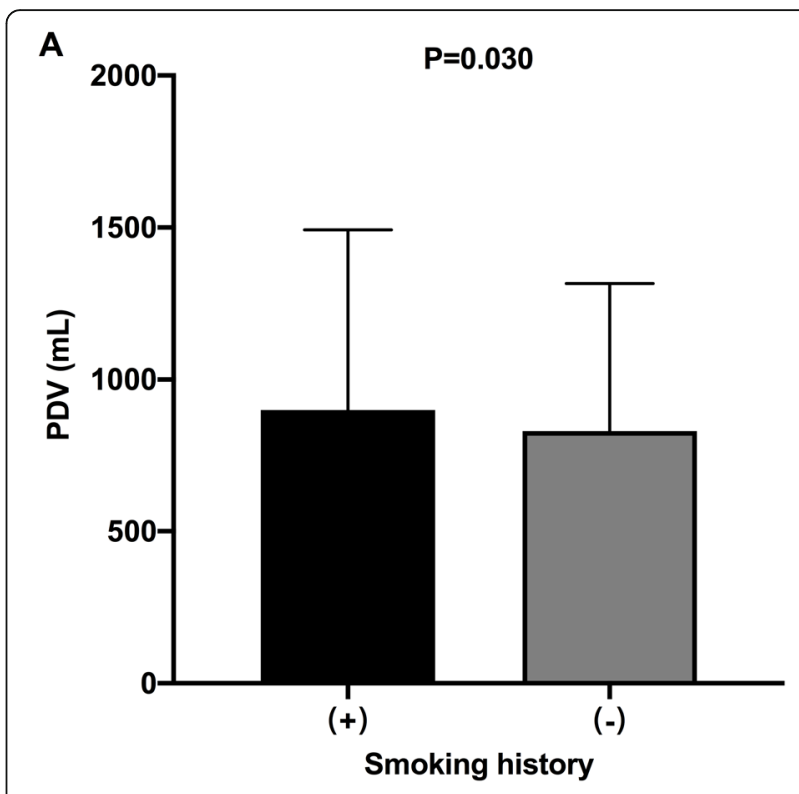

B

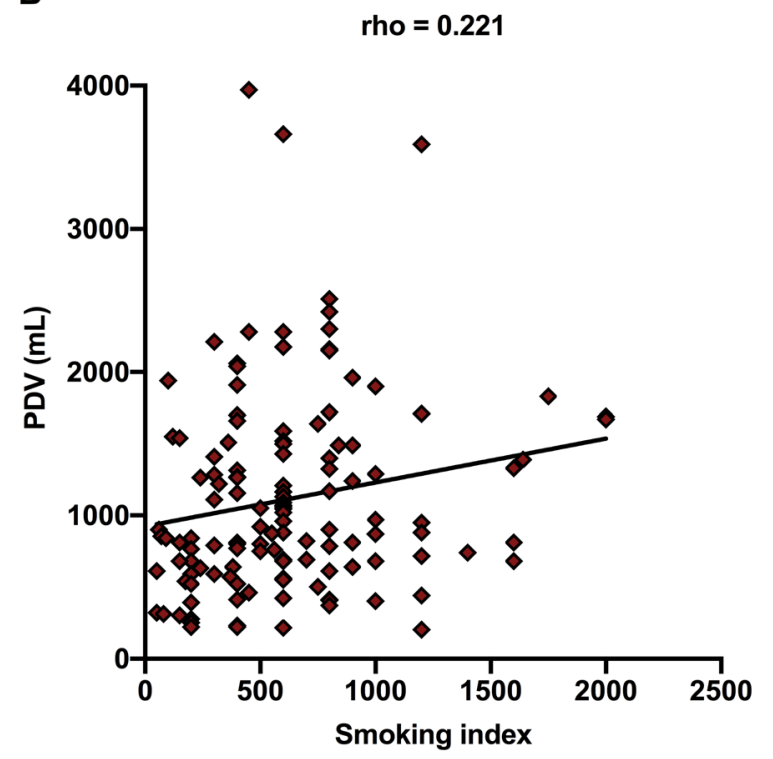

Fig. 4 The comparison of PDV between patients with and without smoking history, and the correlation between the smoking index and PDV in patients with smoking history. a The median PDV of patients with smoking history was higher than that of never smokers (900 ml vs. $830 \mathrm{ml} ; P=0.030$ ). b The smoking index showed a positive correlation with PDV in patients with smoking history, and the correlation coefficient (rho) was 0.221. PDV pleural

drainage volume

effective indicator of bronchiole expansion function and pulmonary compliance, and reduction in FEV1\% reflects the degree of alveolar hyperinflation and subsequent physiopathological decrease in the pulmonary vascular bed, which can aggravate postoperative microvascular filtration. A previous investigation on the operative patients also suggested a causative relationship between 
Table 3 Comparison of PDV based on factors with $P<0.1$ from categorical variables

\begin{tabular}{lll}
\hline Factors & PDV (ml, IQR) & $P$ value \\
\hline Smoking history & & 0.030 \\
With & $900(640-1493)$ & \\
Without & $830(550-1315)$ & \\
Surgical location & & \\
LUL & $835(552.5-1384)$ & \\
LLL & $920(610-1510)$ & \\
RUL & $800(525-1210)$ & \\
RML & $660(430-1020)$ & \\
RLL & $880(630-1435)$ & \\
Surgical location & & \\
Upper or middle lobe & $805(540-1269)$ & \\
Lower lobe & $910(630-1468)$ & \\
\hline
\end{tabular}

PDV pleural drainage volume, IQR interquartile range, LUL left upper lobe, LLL left lower lobe, $R U L$ right upper lobe, $R M L$ right middle lobe, $R L L$ right lower lobe

the decrease in compliance and the perturbation in pleuro-pulmonary fluid balance, which might lead to an increase in pleural effusion [16].

LVEF, an index of left ventricular systolic function, was also found to be a predictor of PDV. One possible explanation is that decreased left-sided cardiac function increased the hydrostatic pressure in the pulmonary circulation and pulmonary edema promoted pleural fluid filtration. In addition, secondary pulmonary edema could also aggravate the hypoxia and inflammation of the residual lung, which further increased the PDV [21-23].

The relationship between TP and pleural transudate has been adequately studied in previous research. Lower serum protein decreased the serum colloid osmotic pressure, which resulted in a higher PDV as a result of increased filtration and decreased reabsorption $[14,24,25]$.

Patients who underwent lower lobectomy had higher PDV in our research, and this finding was in accordance with that reported by Hristova et al. and Kouritas et al. [18, 26, 27]. Increased PDV after lower lobectomy might be due to larger residual space after removal of the lower lobe than the upper or middle lobe, subsequently causing a greater reduction in the vascular bed and pleural reabsorption area as well as greater over-inflation and blood flow redistribution in the residual lung, which resulted in greater filtration of the pleural fluid.

In any case, the amount of pleural drainage cannot be ignored while judging the timepoint of chest tube removal. This study presents the important factors associated with PDV, which can help in perioperative patient management. These factors could be beneficial for alerting the

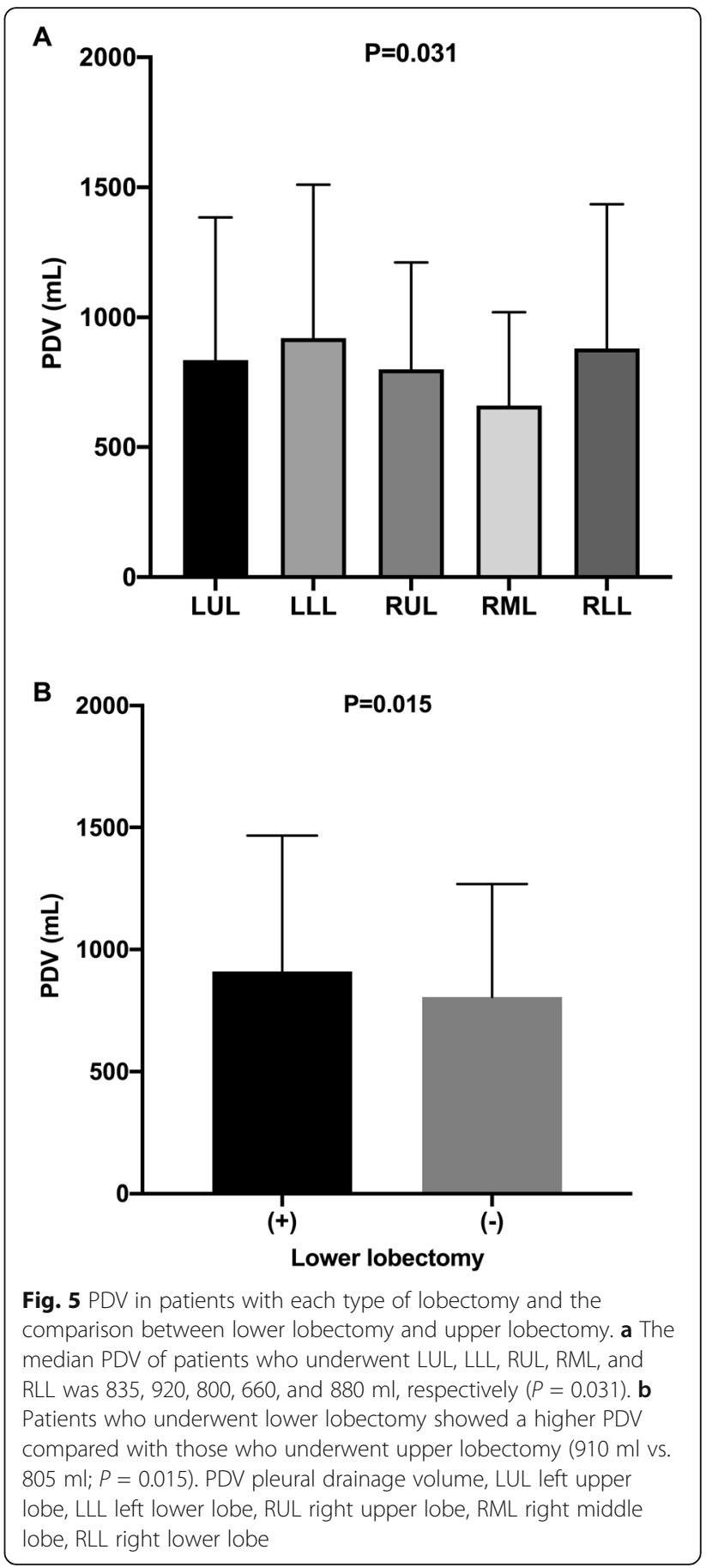

surgeons of incremental PDV and for increasing the awareness. Before the operation, the patients with high predictive PDV should be administered an individualized correction through preoperative therapy and exercise for an enhanced recovery after surgery. After the operation, these predictors can help identify the patients who can safely undergo early chest tube removal after the operation and can provide evidence for differentiated and individualized chest tube management. 
Table 4 Multivariate regression analysis of PDV

\begin{tabular}{lll}
\hline Factors & Regression coefficients & $P$ value \\
\hline Age & 0.203 & $<\mathbf{0 . 0 0 1}$ \\
FEV1\% & -0.225 & $<\mathbf{0 . 0 0 1}$ \\
LVEF & -0.258 & $\mathbf{0 . 0 1 1}$ \\
TP & -0.112 & $\mathbf{0 . 0 1 3}$ \\
Lower lobectomy & 0.109 & $\mathbf{0 . 0 1 6}$
\end{tabular}

PDV pleural drainage volume, FEV1\% forced expiratory volume in $1 \mathrm{~s} \%$ predicted, $L V E F$ left ventricular ejection fraction, $T P$ serum total protein

\section{Limitations}

Although this study collected clinical data prospectively, it was a retrospective study. In addition, as the dependent variable (PDV) was continuous, we could not perform a logistic regression analysis to define the cutoff value for each independent variable. In our future study, we plan to define the cut-off value for each independent variable.

\section{Conclusions}

It is possible to identify the predictive factors associated with an incremental risk of PDV after uniportal VATS lobectomy for NSCLC, and they can be used to tailor individualized safe chest tube management.

\section{Abbreviations}

PDV: Pleural drainage volume; VATS: Video-assisted thoracic surgery; NSCL C: Non-small cell lung cancer; IQR: Interquartile range; BMI: Body mass index; FEV1\%: Forced expiratory volume in $1 \mathrm{~s} \%$ predicted; DLCO\%: Carbon monoxide lung diffusion capacity \% predicted; LVFS: Left ventricular fractional shortening; LVEF: Left ventricular ejection fraction; AST: Aspartate aminotransferase; ALT: Alanine aminotransferase; TP: Serum total protein; ALB: Serum albumin; CRE: Serum creatinine; BUN: Blood urea nitrogen; PT: Prothrombin time; APTT: Activated partial thromboplastin time; $\Pi$ T: Thrombin time; FlB: Fibrinogen; INR: International normalized ratio; RBC: Red blood cell count; WBC: White blood cell count; PLT: Platelet count; Hb: Hemoglobin; ESR: Erythrocyte sedimentation rate; TNM: Tumor, node, metastasis; LUL: Left upper lobe; LLL: Left lower lobe; RUL: Right upper lobe; RML: Right middle lobe; RLL: Right lower lobe
\end{abstract}

\section{Acknowledgments}

We thank Dr. Shang-ning Wang for his valuable effort in collecting the data.

\section{Authors' contributions}

MT collected the clinical information of patients, performed the statistical analysis, and completed the writing of the manuscript; $\lrcorner$ assisted in collecting the patients' clinical information and performing the statistical analysis; ST assisted in revising the statistical methods of the investigation; XG assisted in modifying the manuscript; WL designed the main study and critically revised the manuscript. The author(s) read and approved the final manuscript.

\section{Funding}

Jilin Province Scientific and Technological Department, International Scientific and Technological Cooperation Project (20190701043GH)

\section{Availability of data and materials}

The data used and/or analyzed during the current study were obtained from the Department of Thoracic Surgery, the First Hospital of Jilin University. The data are available from the corresponding author on reasonable request.

\section{Ethics approval and consent to participate}

The present study was reviewed and approved by Ethics Committee of The First Hospital of Jilin University (Changchun, China). Informed consent for use of the medical data in this study was obtained from the patients.

\section{Consent for publication}

Not applicable.

\section{Competing interests}

The authors declare that they have no competing interests.

\section{Author details}

${ }^{1}$ Department of Thoracic Surgery, The First Hospital of Jilin University, 71 Xinmin Street, Changchun, Jilin 130021, China. ${ }^{2}$ Department of Division of Clinical Research, The First Hospital of Jilin University, Changchun, Jilin 130021, China.

Received: 15 April 2020 Accepted: 1 July 2020

Published online: 08 July 2020

\section{References}

1. Gomez-Caro A, Roca MJ, Torres J, Cascales P, Terol E, Castaner J, Pinero A, Parrilla P. Successful use of a single chest drain postlobectomy instead of two classical drains: a randomized study. Eur J Cardiothorac Surg. 2006;29:562-6.

2. Okur E, Baysungur V, Tezel C, Sevilgen G, Ergene G, Gokce M, Halezeroglu S. Comparison of the single or double chest tube applications after pulmonary lobectomies. Eur J Cardiothorac Surg. 2009;35:32-5 discussion 35-36.

3. Molins L, Fibla JJ, Perez J, Sierra A, Vidal G, Simon C. Outpatient thoracic surgical programme in 300 patients: clinical results and economic impact. Eur J Cardiothorac Surg. 2006;29:271-5.

4. Talmor M, Hydo L, Gershenwald JG, Barie PS. Beneficial effects of chest tube drainage of pleural effusion in acute respiratory failure refractory to positive end-expiratory pressure ventilation. Surgery. 1998;123:137-43.

5. Utter $\mathrm{GH}$. The rate of pleural fluid drainage as a criterion for the timing of chest tube removal: theoretical and practical considerations. Ann Thorac Surg. 2013;96:2262-7.

6. Waldhausen JH, Cusick RA, Graham DD, Pittinger TP, Sawin RS. Removal of chest tubes in children without water seal after elective thoracic procedures: a randomized prospective study. J Am Coll Surg. 2002;194: 411-5.

7. Pacanowski JP, Waack ML, Daley BJ, Hunter KS, Clinton R, Diamond DL, Enderson BL. Is routine roentgenography needed after closed tube thoracostomy removal? J Trauma. 2000;48:684-8.

8. Dev SP, Nascimiento B Jr, Simone C, Chien V. Videos in clinical medicine. Chest-tube insertion. N Engl J Med. 2007;357:e15.

9. Bjerregaard LS, Jensen K, Petersen RH, Hansen HJ. Early chest tube removal after video-assisted thoracic surgery lobectomy with serous fluid production up to $500 \mathrm{ml} /$ day. Eur J Cardiothorac Surg. 2014;45:241-6.

10. Olgac G, Cosgun T, Vayvada M, Ozdemir A, Kutlu CA. Low protein content of drainage fluid is a good predictor for earlier chest tube removal after lobectomy. Interact Cardiovasc Thorac Surg. 2014;19:650-5.

11. Nakanishi R, Fujino $Y$, Yamashita T, Oka S. A prospective study of the association between drainage volume within 24 hours after thoracoscopic lobectomy and postoperative morbidity. J Thorac Cardiovasc Surg. 2009;137: 1394-9.

12. Goldstraw P, Chansky K, Crowley J, Rami-Porta R, Asamura H, Eberhardt WE, Nicholson AG, Groome P, Mitchell A, Bolejack V. The IASLC lung cancer staging project: proposals for revision of the TNM stage groupings in the forthcoming (Eighth) edition of the TNM classification for lung cancer. J Thorac Oncol. 2016;11:39-51.

13. Miserocchi G. Mechanisms controlling the volume of pleural fluid and extravascular lung water. Eur Respir Rev. 2009;18:244-52.

14. Zocchi L. Physiology and pathophysiology of pleural fluid turnover. Eur Respir J. 2002;20:1545-58.

15. Brunelli A, Beretta E, Cassivi SD, Cerfolio RJ, Detterbeck F, Kiefer T, Miserocchi G, Shrager J, Singhal S, Van Raemdonck D, Varela G. Consensus definitions to promote an evidence-based approach to management of the pleural space. A collaborative proposal by ESTS, AATS, STS, and GTSC. Eur J Cardiothorac Surg. 2011;40:291-7. 
16. Salito C, Bovio D, Orsetti G, Salati M, Brunelli A, Aliverti A, Miserocchi G. Effect of lung resection on pleuro-pulmonary mechanics and fluid balance. Respir Physiol Neurobiol. 2016;221:35-40.

17. Miserocchi G, Beretta E, Rivolta I. Respiratory mechanics and fluid dynamics after lung resection surgery. Thorac Surg Clin. 2010;20:345-57.

18. Hristova R, Pompili C, Begum S, Salati M, Kefaloyannis M, Tentzeris V, Papagiannopoulos K, Brunelli A. An aggregate score to predict the risk of large pleural effusion after pulmonary lobectomy. Eur J Cardiothorac Surg. 2015;48:72-6.

19. Kosugi S, Kanda T, Yajima K, Ishikawa T, Sakamoto K. Risk factors influencing the pleural drainage volume after transthoracic oesophagectomy. Eur J Cardiothorac Surg. 2013;43:1116-20

20. Oakley R, Tharakan B. Vascular hyperpermeability and aging. Aging Dis, 2014;5:114-25.

21. Miserocchi G, Passi A, Negrini D, Del Fabbro M, De Luca G. Pulmonary interstitial pressure and tissue matrix structure in acute hypoxia. Am J Physiol Lung Cell Mol Physiol. 2001;280:L881-7.

22. Kroegel C, Antony VB. Immunobiology of pleural inflammation: potential implications for pathogenesis, diagnosis and therapy. Eur Respir J. 1997;10: 2411-8.

23. Wiener-Kronish JP, Goldstein R, Matthay RA, Biondi JW, Broaddus VC, Chatterjee K, Matthay MA. Lack of association of pleural effusion with chronic pulmonary arterial and right atrial hypertension. Chest. 1987;92:967-70.

24. Broaddus VC, Light RW. What is the origin of pleural transudates and exudates? Chest. 1992;102:658-9.

25. Eid AA, Keddissi Jl, Kinasewitz GT. Hypoalbuminemia as a cause of pleural effusions. Chest. 1999;115:1066-9.

26. Kouritas VK, Zissis C, Bellenis I. Variation of the postoperative fluid drainage according to the type of lobectomy. Interact Cardiovasc Thorac Surg. 2013; 16:437-40.

27. Kouritas VK, Hatzoglou C, Gourgoulianis Kl, Molyvdas PA. Pleural electrophysiology variations according to location in pleural cavity. Interact Cardiovasc Thorac Surg. 2009:9:391-4.

\section{Publisher's Note}

Springer Nature remains neutral with regard to jurisdictional claims in published maps and institutional affiliations.

Ready to submit your research? Choose BMC and benefit from:

- fast, convenient online submission

- thorough peer review by experienced researchers in your field

- rapid publication on acceptance

- support for research data, including large and complex data types

- gold Open Access which fosters wider collaboration and increased citations

- maximum visibility for your research: over $100 \mathrm{M}$ website views per year

At $\mathrm{BMC}$, research is always in progress.

Learn more biomedcentral.com/submissions 